\title{
Marking Topic or Marking Case: A Comparative Investigation of Heritage Japanese and Heritage Korean
}

\section{Citation}

Laleko, Oksana and Maria Polinsky. 2013. Marking Topic or Marking Case: A Comparative Investigation of Heritage Japanese and Heritage Korean. Heritage Language Journal 10(2): 40-64.

\section{Permanent link}

http://nrs.harvard.edu/urn-3:HUL.InstRepos:11879946

\section{Terms of Use}

This article was downloaded from Harvard University's DASH repository, and is made available under the terms and conditions applicable to Open Access Policy Articles, as set forth at http:// nrs.harvard.edu/urn-3:HUL.InstRepos:dash.current.terms-of-use\#OAP

\section{Share Your Story}

The Harvard community has made this article openly available. Please share how this access benefits you. Submit a story. 


\title{
Marking topic or marking case: \\ A comparative investigation of Heritage Japanese and Heritage Korean·
}

\author{
Oksana Laleko (SUNY New Paltz) \\ Maria Polinsky (Harvard)
}

\begin{abstract}
In this paper, we examine the relationship between grammatical and discourse-related domains of linguistic organization in heritage speakers by comparing their knowledge of categories mediated at different structural levels: grammatical case marking, which is mediated within the structure of the clause, and the marking of information structure, grammatically mediated at the syntax-discourse interface. To this end, we examine the knowledge of case and topic particles in heritage speakers and L2 learners of Japanese and Korean as assessed through a series of rating tasks. We find that heritage speakers in both languages experience different degrees of difficulty with elements that belong to different linguistic modules: phenomena which involve semantic and discourse computation are found to be more difficult than phenomena governed primarily by structural syntactic constraints.
\end{abstract}

\section{Setting the stage}

Existing cross-linguistic studies of heritage languages have unraveled a range of grammatical properties that pose difficulties to heritage speakers, allowing us to make preliminary generalizations about the overall linguistic architecture of heritage speakers'

- The authors thank Sun-Hee Bae, Shin Fukuda, Sandy Kim, Jenny Lee, Hiroki Nomoto, Steve SanPietro, Aika Taguchi, and three anonymous reviewers whose help with various aspects of this project is deeply appreciated. We are grateful to the audiences at the Sixth Heritage Language Research Institute, Chicago Bilingualism Forum, and the Center for Language Science at PennState for valuable comments on this work. The research presented here was supported by the Center for Advanced Study of Language (CASL) at the University of Maryland, the College of Liberal Arts and Sciences at SUNY New Paltz, and the Faculty of Arts and Sciences at Harvard University, and the National Heritage Language Resource Center at UCLA. We are solely responsible for all the errors.

Abbreviations: ACC-accusative; AND-adnominal; COMP-complementizer; $\mathrm{CP}$ complementizer phrase; DECL_-declarative; DP-determiner phrase; GEN_-genitive; IPinflectional phrase; NEG-negation; NOM-nominative; PASS - passive; PRS - present; TOP-topic. 
grammars and formulate more precise questions for future investigations. Due to a wide variation in proficiency (for a detailed discussion of the proficiency continuum in heritage languages, see Polinsky \& Kagan, 2007), not all phenomena may be of equal difficulty to all heritage language speakers, and not all heritage speakers can be expected to exhibit divergences from the baseline language, i.e., the language of the monolingual native speakers, on all variables. At the same time, researchers have noticed intriguing parallels among typologically dissimilar languages with respect to aspects of linguistic knowledge that present systematic challenges in heritage language development. Taken together, these observations compel us to look at speakers of varying proficiency across different languages.

Lower proficiency heritage speakers have been repeatedly found to exhibit systematic deficits in two large areas: first, the knowledge and use of inflectional morphology, and second, the knowledge and use of complex syntactic structures. These deficits manifest themselves in difficulties with such grammatical phenomena as case, gender, agreement, verbal aspect, mood, and long-distance dependencies such as relative clauses, wh-questions, and passives (Benmamoun et al., 2010; Montrul, 2002; Montrul et al., 2008; Polinsky, 1997, 2006; 2008a, b; 2011; Rothman, 2007; Song et al., 1997, inter alia). Deficits in morphosyntax and in complex syntactic structures have been documented for a variety of heritage languages, including Russian, Spanish, Portuguese, Hindi, Hungarian, Korean, Arabic, and English.

Less is known about the linguistic competence of heritage speakers at the upper end of the proficiency continuum: these people have remained in the background of linguistic investigations of heritage language competence until recently. A typical assumption is that these speakers understand everything and may have small register problems (Kagan \& Bermel, 2000). More fluent speakers definitely exhibit fewer surface morphosyntactic deviations from the baseline, as evidenced most notably by virtually error-free production and comprehension, at least as compared to their low proficiency brethren. Whatever deviations from the baseline they may have are harder to observe and require deeper probing into production and comprehension (see Laleko, 2010 for additional discussion). Such probing is worthwhile, though, because it uncovers noteworthy linguistic phenomena and may uncover trends and tendencies barely visible in the baseline.

In a study of advanced heritage speakers' knowledge of the aspectual system in Russian, Laleko (2010) found that the specific areas of difficulty in these populations were associated with aspectual functions mediated at the highest structural levels, particularly those that interface with discourse-pragmatics and encode information structure. Even in the absence of morphosyntactic errors in production, advanced heritage speakers of Russian had difficulty with contexts that involved apparent optionality, where both aspectual forms were available and where the choice between perfective and imperfective had to be resolved by contextual and pragmatic factors. In these conditions, advanced heritage speakers systematically diverged from the baseline group; in particular, they demonstrated reduced knowledge of discourse-level, but not sentence-level, functions of the imperfective aspect. Thus Laleko's study showed that an 
investigation of high proficiency heritage speakers is expedient for understanding the full range of properties manifested in heritage grammars.

In this paper, we continue with an examination of high proficiency heritage speakers, analyzing a set of linguistic phenomena that involve interactions of clausal, sentential, and contextual domains. The phenomena we chose for this next investigation are the marking of topic vs. the marking of the nominative in Japanese and Korean. In particular, we examine the conditions on the use of overt and zero marking of topics and nominative arguments in these two languages.

The emphasis on the information-structural component offers a theoretical gain. On the theoretical plane, our study would allow us to gain a better understanding of the hierarchy of structure-building and interpretation proposed by a number of researchers (Kornneef, 2008; Reuland, 2011, a.o.). Linguistic relations can be encoded in syntax, in semantics, or discourse. NARROW SYNTAX is the core of the syntactic computational system. By assumption (Chomsky, $1995,2000,2001)$, narrow syntax, also called the computational system of human language, is invariant across languages and builds syntactic representations. This system includes a set of structure-building mechanisms (Agree, Merge, and Move) that are assumed to be universal across languages.

The output of narrow syntax is augmented with vocabulary required for the structure to be read by the semantic inference system (sometimes called LOGICAL SYNTAX, e.g., Reinhart, 2006; Reuland, 2011:30-34). It corresponds to logical form in Principles \& Parameters frameworks - the syntactic representation enriched by further vocabulary to fully represent logical structure. It is helpful to think of the forms encoded in logical syntax as semantic dependencies to distinguish them from properly syntactic and discourse structures. The DISCOURSE component of the grammar situates the logical syntax in the larger context that includes world knowledge, speaker intent, and the full linguistic context. Discourse is where reference relations are established.

A number of researchers, using different terminology at times, have arrived at the following hierarchy in the economy of linguistic encoding (Givon, 1979; Langacker, 2000; Reinhart, 1983, 2006; Grodzinsky \& Reinhart, 1993; Frazier \& Clifton, 1996; Kornneef, 2008; Reuland 2011, a.o.):

$$
\text { Narrow syntax }<\text { logical syntax }(\mathrm{C}-\mathrm{I} \text { interface })<\text { discourse }
$$

If we follow the ideas advanced by Reuland (2011) and Koornneef (2008), linguistic encodings formed in components farther to the left on the hierarchy in (1) are "less costly" in terms of processing and construal than those toward the right. These predictions have been formulated for competent speakers, who have fully acquired a given language. For the purposes of this paper, such a conception suggests that we should expect heritage speakers to show different degrees of difficulty with elements that belong in the different components of the hierarchy in (1). In particular, we expect that phenomena which involve semantic and discourse 
computation will be more difficult than phenomena governed primarily by structural syntactic constraints. Within the semantic and discourse components, we expect further difference: Sgemantic computation should be easier than the computation of discourse-related elements.

The choice of alternations that involve overt vs. zero marking is also not accidental. Existing descriptions of heritage grammars have repeatedly underscored a general tendency toward redundancy of expression, observed in production as well as in comprehension (see Polinsky, 2006; Benmamou et al., 2011). To put it differently, heritage speakers have the greatest trouble with linguistic segments that are covert, not spelled out, and represented by some kind of a silent exponent, be they at the level of morphological encoding (null morphemes), silent pronouns, or contextual deletion such as ellipsis. Below we will refer to this difficulty as the "silent problem." In fact, difficulty with null elements may be one of the main reasons why low proficiency heritage speakers show morphosyntactic deficits. It is yet to be determined if high proficiency heritage language is completely immune to the "silent problem" or if it simply has not been subject to enough scrutiny in that regard. The current study offers us an opportunity to address the "silent problem" in high proficiency speakers.

In sum, it is our goal in this paper to examine the role of the hierarchy of encoding (1) and the "silent problem" in high-proficiency heritage speakers. In order to meet this goal, we will examine the use of topic vs. nominative marking in Japanese and Korean. Topic expressions are relevant for understanding the relationships between the syntactic component, the semantic interpretation, and discourse. Thus by examining the interaction between topics and subjects (in the nominative) we can target different domains represented in (1) above. Furthermore, since Japanese and Korean have a number of conditions where the topic or nominative marker can be omitted, we can also to address the "silent problem" in relatively well-understood contexts.

As bilinguals, heritage speakers have a number of similarities to first language learners, but they also show some parallels to second language speakers, including transfer from their dominant language. A number of researchers have underscored the "in-between" position of heritage speakers on the continuum of language acquisition (cf. Montrul, 2008). In order to be able to evaluate and interpret our findings within the larger context of language acquisition scenarios, we have broadened the scope of our investigation to include second language learners of Japanese and Korean.

The most apparent parallel between heritage and second language populations is that for both groups, the target language represents a non-dominant variety in an incomplete state of attainment, and if we assume the monolingual baseline variety to be the measure of complete language mastery, then both groups appear to fall short of this target in ways that are still quite poorly understood. Perhaps for this reason, heritage and second language learners often end up being placed together in classroom settings, despite the fact that such surface-level categorization often proves to be ineffective from a pedagogical perspective. Recent linguistic studies have begun to unravel contrasts that point to important systematic differences in the nature of linguistic deficits exhibited by speakers in the two groups, and here we hope to provide additional insights into these differences. Thus, data from heritage language speakers are 
compared not only with the control group of native speakers, but also with results obtained from age-matched second language learners of Japanese and Korean.

The rest of the paper is structured as follows. Section 2 provides an overview of topic vs. nominative marking in Japanese and Korean, with an emphasis on the similarities across both languages. It also discusses the contexts where the topic and nominative markers can be omitted. Section 3 introduces the logic of our comprehension experiment, outlines its predictions, and describes our materials. Section 4 presents the details and results of the experiment. Section 5 provides additional discussion of the main findings, and Section 6 lays out our conclusions and outstanding questions.

\section{Topic and nominative marking in Japanese and Korean}

As stated earlier, our primary goal in this investigation is to compare heritage speakers' knowledge of categories mediated at different structural levels: grammatical case marking, which is mediated within the structure of the IP projection, and the marking of information structure, syntactically mediated in the CP domain. To do so, we examine the knowledge of case and topic particles in heritage speakers of Japanese and Korean, two languages that exhibit interesting parallels with respect to their syntactic organization. As topic-prominent languages in the sense of Li \& Thompson (1976), the two languages have overt means of marking the distinction between new information and given (shared) information in addition to grammatical functions such as subject or object. The following examples from Japanese and Korean illustrate the phenomena:

(2) a.

$\begin{array}{ll}\text { Sakana-wa tai-ga } & \text { oisii. } \\ \text { fish-TOP red snapper-NOM delicious } & \\ \text { 'Speaking of fish, red snapper is delicious' }\end{array}$

b. Sayngsen-un yene-ka massiss-ta.

Korean

fish-TOP salmon-NOM delicious-DECL

'Speaking of fish, salmon is delicious.'

Both languages use particles to encode the relevant contrasts: -wa (Japanese) and -nun/-un (Korean) attach to the noun phrase, which serves as the topic of the sentence, while -ga (Japanese) and $-i /-k a$ (Korean) mark its grammatical subject.

There are a number of similarities between Japanese and Korean with respect to how the particles are used, and in what follows we will outline only some of these parallels. In both languages, topic markers can mark a generic expression, interpreted as referring to a general class of entities, as shown in (3), an anaphoric noun phrase, which is linked to prior discourse via a linguistic or contextual antecedent, as in (4), or a contrastive topic, illustrated in (5) below (Kuroda, 1965, 2005; Kuno, 1973; Choi, 1999). 
(3) a. Kami-wa ki-kara tsuku-rare-masu.

Japanese paper-TOP tree-from make-PASS-be

'Paper is made from trees.'

b. Congi-nun namwu-eyse mantule

ci-n-ta.

Korean paper-TOP tree-from make

PASS-PRS-DECL

'Paper is made from trees.'

(4) a. Watashi-wa sengetsu-hajimete chuugoku-o otozuremashi-ta. Japanese I-TOP last month-first time China-ACC visit-PAST

'I visited China for the first time last month.'

Ima chugoku-wa ichiban sukina kuni-desu

now China-TOP first favorite country-is

'Now, China is my favorite country.'

b. Na-nun cinan tal-cheumulo cwungkwuk-ul

pangmwunhay-ss-ta. Korean

I-TOP last month-first time China-ACC

visit-PAST-DECL

'I visited China for the first time last month.'

$\begin{array}{lclc}\text { Cikum cwungkwuk-un } & \text { kacang } & \text { cohaha-nun nala-ita } \\ \text { now China-TOP } & \text { first } & \text { like-ADN country-is } \\ \text { 'Now, China is my favorite country.' } & & \end{array}$

Since Kuno (1973), it has become common to group generic and anaphoric topics into a single class of thematic topics based on a number of shared properties, including their semantic, phonological, and syntactic behavior. Thematic topics are interpreted as what the rest of the sentence is about (cf. Reinhart, 1981); they are prosodically neutral and tend to occupy a clauseinitial syntactic position in root clauses (with few exceptions, thematic topics do not appear in subordinate clauses). Some analyses maintain that thematic topics are best understood as discourse-level rather than sentence-level phenomena. For example, for Maynard (1980), thematic $w a$ in Japanese is a discourse organizing device that is used for establishing discourse cohesion and expressing the speaker's perspective on the situation at large.

Unlike thematic topics, contrastive topics pick out entities from a set of alternatives and thus always implicate a contrastive relationship between two or more elements within a sentence, as shown in (5), or between an explicitly mentioned entity and one that is not contextually present but implied, as in (6) below. Contrastive topics are less restricted syntactically in their distribution than thematic topics and can occur in root clauses, as in (5), as well as in subordinate 
clauses, as in (6). Contrastive topics always carry emphatic stress; in other words, they are marked by a combination of prosody and morphology.

$\begin{array}{lllll}\text { (5) a. } & \text { Watashi-wa } & \text { hudan hougaku-wa } \quad \text { kikimasu } & \text { ga } & \text { Japanese } \\ \text { I-TOP } & \text { usually Japanese_music-TOP listen } & \text { but } & \end{array}$

yougaku-wa kiki-masen.

Western music-TOP listen-NEG

'I usually listen to Japanese music but I do not listen to Western music.'

$\begin{array}{clll}\text { b. Na-nun } & \text { pothong ilpon_umak-un } & \text { tut-ciman } & \text { Korean } \\ \text { I-TOP } & \text { usual } & \text { Japanese_music-TOP } & \text { listen-though }\end{array}$
(6) a. Taroo-wa [Hikari-wa kirei-da to] omou. Japanese Taroo-TOP Hikari-TOP beautiful-be-COMP think
'Taroo believes that Hikari [as opposed to someone else] is beautiful'
b. Taroo-nun [Hikari-nun alumtap-ta-ko] sayngkakhanta. Korean Taroo-TOP Hikari-TOP beautiful-be-COMP think
'Taroo believes that Hikari [as opposed to someone else] is beautiful'

Because contrastive topics can be generic, anaphoric, or neither, in some contexts prosody serves as the only means to differentiate them from thematic topics (Kuno, 1973; Maynard, 1980; Nakanishi, 2001). For example, the wa-marked DP 'paper' in (3) above is interpreted as a thematic topic when uttered with a default neutral intonation, but it may also imply a contrast when a prominent contrastive intonation is present ("Paper, as opposed to something else..."). Such optionality is absent when the topic markers occur in embedded clauses, as in (6) above, where the $w a$-marked DP can only be interpreted contrastively.

The nominative case particle in Japanese as well as in Korean is also associated with at least two distinct functions, descriptive and exhaustive, illustrated in examples (7) and (8) below (from Kuno, 1973). Under the neutral description reading in (7), the subject marker, which is prosodically unmarked, is analyzed strictly as a case marker, without additional interpretations. Thus, the utterance is acceptable without any prior context. However, when combined with a prominent stress, the subject particle produces an exhaustive listing reading, associated with narrow focus (i.e., focus on a particular DP that does not project to any of the higher constituents). Under the narrow focus reading, the subject DP in (8) can only be interpreted as new information being introduced into discourse, for example, as an answer to a wh-question or another context soliciting an exhaustive reading. In Lambrecht's (1994) terms, the contrast 
between (7) and (8) would be captured by a distinction between sentence focus and argument focus, respectively.

(7)

$\begin{array}{ll}\text { Ame-ga } & \text { hutte imasu. } \\ \text { rain-GA falling is } \\ \text { 'It is raining' }\end{array}$

Japanese

b. Pi-ka

rain-KA

nayli-ko

iss-ta.

Korean

'It is raining'

(8)

$\begin{array}{lll}\text { a. John-ga } & \text { gakusei } & \text { desu. } \\ \text { John-GA } & \text { student } & \text { is }\end{array}$

be-DECL

'It is John who is a student' ('Of all the people under discussion, John and only John is a student')

b. John-i

haksayng iss-ta.

Korean

John-I

student

be-DECL

'It is John who is a student' ('Of all the people under discussion, John and only John is a student')

A traditional distinction drawn between the topic marker and the subject marker often explicitly links the topic marker with old information and the subject marker with new information (Chafe, 1973; Inoue, 1983). However, there are some problems with this approach, which assumes a symmetrical distribution of the two markers along the information-structural scale. While ga-marked DPs indeed tend to introduce new information in Japanese, the association of the nominative case marker with information structure is at best only indirect: Since Japanese topics are marked with $w a$, it is the absence of $w a$-marking rather than the presence of the nominative case marker that gives rise to the new information reading to a $g a$ marked DP. In Korean, the division of labor between the topic particle and the nominative case particle differs from that in Japanese in that the topic marker is overall more restricted in its distribution. Since both old and new DPs can be marked with the nominative case particle, the topic marker is associated first and foremost with discourse prominence: Use of the topic particle marks referents prominent in the discourse scene and the absence of the topic particle marks nonprominent referents (Shimojo \& Choi, 2000). A similar account was proposed by Maynard (1980) for some discourse-level functions of the topic marker in Japanese.

Further parallels between the two languages can be drawn on the basis of particle ellipsis. In Japanese as well as in Korean, case and topic particles may be omitted in spoken registers, with lower levels of formality corresponding to higher rates of particle omissions (Kuno, 1972; Tsutsui, 1984; Yatebe, 1999; Shimojo, 2006): 
(9)

$\begin{array}{llll}\text { a. Kicchin-ni oishii pai (ga) } & \text { arimasuyo. } \\ \text { kitchen-in delicious pie (NOM) } & \text { Japanese } \\ \text { 'There is a delicious pie in the kitchen.' } & \end{array}$

b. Pwuek-ey masissnun pai (ka)

iss-ta.

Korean

kitchen-in delicious pie (NOM) be-DECL

'There is a delicious pie in the kitchen.'

a. Kino-no-yoru tomodachi-to issyo-ni mi-ta
yesterday-GEN-night friends-and together-with watch-PAST
eiga (wa) totemo $\quad$ yoka-tta.
movie (TOP) very good-PAST
'The movie that I watched with my friends last night was very good.'
b. Eceysspam chingwu-wa hamkkey bo-ass-ten Korean yesterday_night friends-and together-with watch-PAST-ADN yenghwa (nun) acwu coha-ess-ta. movie (TOP) very good-PAST-DECL

'The movie that I watched with my friends last night was very good.'

In contexts where both null and overt particle options may be acceptable, the choice between the two options is often governed by subtle discourse-pragmatic and semantic factors. For example, some studies find a link between the occurrence of overt markers and animacy, in that animate DPs allow for a more frequent omission of the marker (see Kim, 2008 for Korean; Kurumada \& Jaeger, 2012 for Japanese).

At the same time, both languages also impose categorical restrictions on the occurrence of zero particles in certain environments. The nominative marker is obligatory with subjects of embedded clauses or when the ga-marked DP has an exhaustive listing interpretation (Shimojo, 2006). The topic marker must be overt when it signals a contrastive relationship (Yatabe, 1999).

Overall, it seems that a certain degree of optionality and presence of multiple pragmatic choices in the use of null and overt particles presents potential challenges for the acquisition of these particles. Existing findings in early L1 acquisition suggest that while the particles begin to appear relatively early in child L1 production (for a comprehensive overview of existing studies, see Clancy, 1985), L1 learners initially exhibit high rates of particle omission, overuse, and misuse and that full mastery of these particles in all of their discourse functions may not be achieved until late in the acquisition process (Ito \& Tahara, 1985).

In both Korean and Japanese, the nominative marker begins to be used consistently earlier than the topic marker. Overuse of the subject particle has been repeatedly documented for early L1 learners of Japanese (Fijimoto, 1977; Takahashi, 1975; Goto, 1988), and the production 
rate of $g a$ has been reported to be adult-like by age 2;5-2;10 (Morikawa, 1997). Nakamura (1993) finds that $g a$ is used more frequently than $w a$ in child narratives despite the fact that $w a$ is used more frequently by adults. Even though children begin to use wa around 18-26 months (Hirakawa, 2004; Okubo, 1967), non-target-like omissions of the topic marker persist until the age of 5 (Nakamura, 1993). This may be a reflection of patterns observed in child-directed speech, where particle ellipsis has been found to be particularly frequent: According to data reported in Clancy (1985), the rates of particle omission in adult speech addressed to young children have been observed to be nearly three times higher than in adult-to-adult interactions, with particularly high rates of wa-omissions (70\%) compared to ga-omissions $(30 \%)$ in childdirected speech. A very similar developmental pattern is documented for the acquisition of the two sets of particles in Korean, where the acquisition of the nominative case marker generally precedes the acquisition of the topic marker by 2-4 months (Kim, 1997). Initially children exhibit a preference for $-k a$ over $-i$ and even use hybrid forms like $-i-k a$ to mark the nominative, but by age 3 the acquisition of the nominative marker is generally complete. Among the various discourse functions of the topic marker, contrastive use of $-(n) u n$ in Korean is exhibited earlier than its thematic use (Kim, 1997).

\section{The study}

\subsection{Rationale and predictions}

In a pilot study of heritage Japanese, Laleko \& Kawamura (2011) examined narratives elicited from heritage and monolingual speakers of Japanese and found that heritage speakers underused the topic marker and overused the nominative case marker (the distribution of other case markers, including the accusative $-o$, dative $-n i$, and genitive $-n o$, was largely parallel to the patterns observed in the baseline group). Prevalence of the nominative marker, whose misuse typically leads to ungrammaticality, over the topic marker, whose misuse generally results in infelicity and triggers fewer categorical judgments, lends additional support to the generalization that optionality, often associated with interface phenomena and dependence on sentence-external contextual factors rather than narrow syntax, presents a special set of difficulties in heritage language acquisition.

In this study, we further tested the interplay between syntactic and information-structural components by eliciting acceptability ratings on the use of topic and nominative markers in Japanese and Korean.

Our hypotheses follow from the two main goals of this study, outlined in the introductory discussion: first, to examine heritage language speakers' knowledge of phenomena mediated at different structural levels; second, to address the "silent problem" by comparing these speakers' knowledge of principles governing the occurrence of null and overt particles. With respect to the first question, if phenomena mediated at the syntax-pragmatics interface are associated with 
more difficulty than phenomena contained within narrow syntax, we can expect heritage speakers to exhibit less accuracy on conditions involving the topic marker compared to those involving the subject marker. In line with this hypothesis, we can further formulate an additional sub-set of predictions, which take into account the three distinct functions of the topic marker (anaphoric, generic, contrastive) and the two functions of the subject marker (descriptive and exhaustive). Anaphoric topics, which establish reference relations in discourse and require discourse tracking, are predicted to be more difficult than contrastive topics, which participate in logical set relations. Generic topics, which are not linked to prior discourse or to another member in a set of alternatives, should be the least difficult. Within the range of functions of the nominative case marker, the neutral description reading is predicted to be easier than the narrow focus reading, which interacts to a greater extent with the information structure and the larger linguistic and non-linguistic context of the utterance.

With respect to the "silent problem," if the emerging generalization that heritage language speakers face greater challenges with null elements holds across languages, we predict better accuracy on conditions involving overt markers compared to conditions involving particle omissions. We therefore expect that null elements will present greater challenges than those overtly expressed.

Finally, given possible similarities between heritage speakers and more advanced second language learners, we chose to compare three groups of subjects: monolingual baseline speakers (controls), heritage speakers, and second language learners. At first blush, one may hypothesize that heritage speakers should be closer to the monolingual baseline than second language learners. However, prior studies have shown that the advantages enjoyed by heritage speakers over second language learners are selective, and different task modalities (e.g., written vs. oral, naturalistic vs. metalinguistic) may reveal different types of advantages in the two populations (cf. Bowls, 2011; Montrul et al. 2008; Montrul \& Perpiñán, 2011). Thus, we do not make a priori assumptions about the anticipated proximity of each group's results relative to the baseline.

\subsection{Materials, method, participants}

In order to explore the relationship between topic and nominative, we conducted an acceptability ratings experiment, which included heritage language speakers ( $\mathrm{N}=29$ for Japanese, $\mathrm{N}=35$ for Korean) and second language learners ( $\mathrm{N}=31$ for Japanese, $\mathrm{N}=16$ for Korean). The summary of the relevant demographic information for the target groups of heritage language speakers (HL) and second language learners (L2) is presented in Table 1 below.

Table 1. Participants

\begin{tabular}{l|ll|ll}
\hline \multirow{2}{*}{ Language } & \multicolumn{2}{|c|}{ KOREAN } & \multicolumn{2}{c}{ JAPANESE } \\
\hline Group & L2 $(\mathrm{N}=16)$ & HL $(\mathrm{N}=35)$ & L2 (N=31) & HL (N=29) \\
Age & 25.8 & 24.5 & 27.5 & 24.75
\end{tabular}




\begin{tabular}{l|ll|ll} 
Age of arrival to U.S. & N/A & $3.2^{1}$ & N/A & 4.0 \\
\hline Age of switch to English & N/A & 3.0 & N/A & 4.8 \\
Daily use of Korean/Japanese (\%) & 23.5 & 29.6 & 12.4 & 22.9 \\
\hline Self-rated proficiency in Korean/Japanese (1-5) & 3.39 & 4.35 & 3.01 & 3.62 \\
\hline
\end{tabular}

Our control groups included age-matched native speakers of Japanese and Korean $(\mathrm{N}=13$ for each language). The materials for the study included 56 sentences in each language, which participants were asked to rate on a 1-5 scale. Ratings were elicited on a set of conditions, including appropriate use of the topic and subject marker; misuse of the markers, including use of the nominative particle in place of the topic particle and vice versa; and appropriate and inappropriate particle omissions. ${ }^{2}$ The study was conducted on Amazon Mechanical Turk (see Gibson et al., 2011; Sprouse, 2011 for details on using Mechanical Turk in linguistic research). Prior to participating in the study, all participants completed a detailed sociolinguistic background questionnaire. ${ }^{3}$

\section{Results}

The results of the experiments were analyzed using a mixed-effects regression model (Gries, 2010). Heritage language speakers were generally more accurate on conditions involving the nominative marker than on conditions involving the topic marker (Fig.1). Thus, our first prediction was borne out for both Korean and Japanese, but with interesting differences between the two languages, to which we return in Section 5 below. Heritage speakers of Korean were significantly closer to the baseline compared to the Korean speakers in the L2 group. In contrast, heritage speakers of Japanese were further away from the Japanese baseline compared to the Korean group and overall patterned with L2 learners of Japanese. The aggregated accuracies for conditions involving the nominative case marker and conditions involving the topic marker are presented in Figure 1 below. Note that the accuracy is measured by distance from the mean baseline ratings (as obtained from native speakers), taken as the zero value.

Figure 1. Mean accuracies for topic (Top) and nominative (Nom) conditions for heritage speakers and L2 learners of Japanese (left) and Korean (right).

1 The discrepancy between the age of arrival (3.2) and the age of switch to English (3.0) is explained by the different populations for which these ages are calculated. Only a subset of heritage speakers were born in Korea.

2 The experimental sentences can be accessed online at: http://dvn.iq.harvard.edu/dvn/dv/polinsky. For each language, the data were normed by twelve native speakers.

3 The questionnaire is also posted online: http://dvn.iq.harvard.edu/dvn/dv/polinsky. 

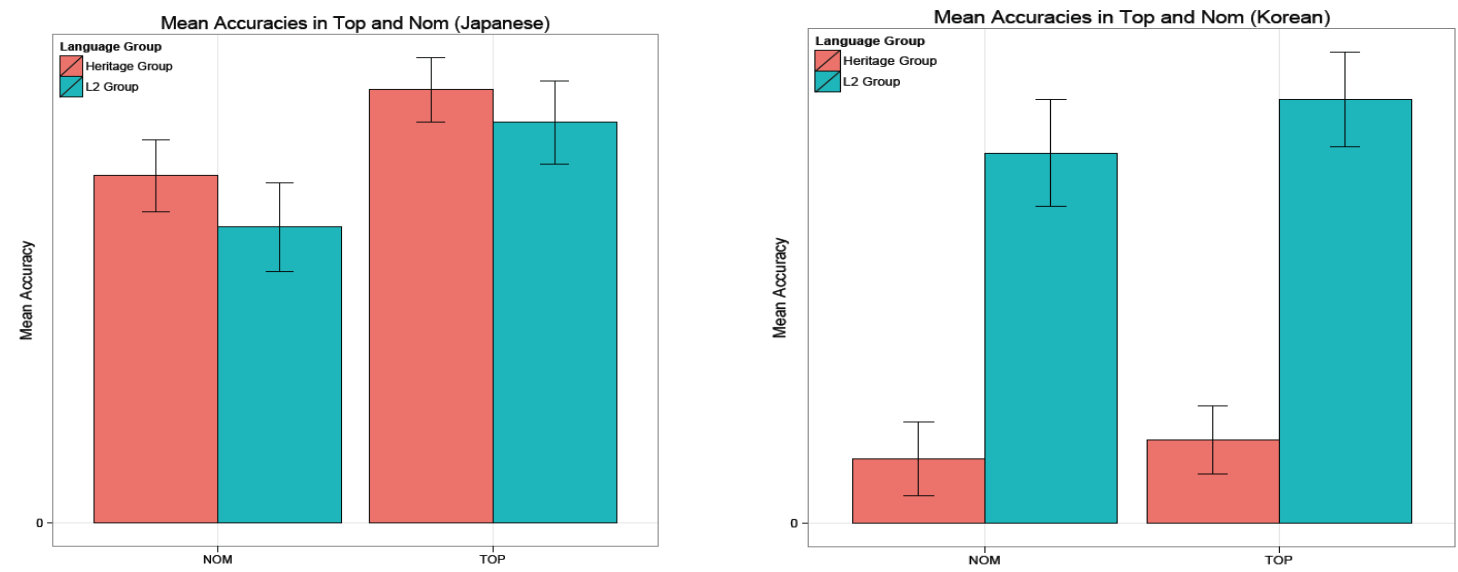

Across-group comparisons reveal that Japanese heritage speakers by and large patterned with second language learners: Differences between the two groups were found to be not significant on all experimental conditions. However, when heritage language speakers and L2 leaners were compared with the baseline speakers in the control group, heritage speakers of Japanese exhibited a small advantage over L2 learners of Japanese on conditions involving particle misuse, where ratings in the heritage language group were closer to those in the baseline group. This advantage was greater on conditions that called for the use of the nominative case particle but where the topic marker was used, resulting in ungrammaticality. Here, the difference between the heritage and baseline groups was not significant $(\mathrm{p}=0.49)$, while the difference between the baseline and L2 groups approached significance $(\mathrm{p}=0.09)$. Apart from this very small advantage exhibited by Japanese heritage speakers over L2 learners, the two target groups were virtually indistinguishable. Both groups significantly diverged from the controls in the following areas: acceptable particle use, where heritage language speakers and L2 learners underrated well-formed sentences with both particles $(\mathrm{p}<0.001)$; unacceptable use of $w a$, where sentences were overrated by participants in heritage and L2 groups $(p<0.0001)$; and unacceptable omissions of $g a$ and $w a$, where the two target groups exhibited significantly higher ratings than those observed in the control group $(\mathrm{p}<0.001)$. These results support both sets of predictions outlined above.

A further in-depth analysis of within-group ratings confirms that Japanese heritage speakers and L2 learners did not exhibit target-like knowledge of contrasts between the subject and topic particles and rules governing their omissions, as evidenced by non-significant differences between conditions targeting contexts for acceptable vs. unacceptable particle use and contexts for acceptable vs. unacceptable particle omissions. In other words, while native speakers of Japanese in the control group were sensitive to contrasts between acceptable and unacceptable sentences in all conditions, heritage speakers and L2 learners in the Japanese group exhibited no target-like knowledge of the linguistic functions of the topic and subject markers and principles that determine when these markers can be omitted.

In contrast to the Japanese group, Korean heritage speakers overall patterned with baseline speakers and were statistically indistinguishable from the controls on all conditions 
except ungrammatical particle omissions, where heritage speakers were less accurate than controls $(\mathrm{p}<0.01)$ but still more accurate than L2 learners, who diverged from the native speakers to a greater extent $(\mathrm{p}<0.00001)$. Once again, this result points to the pervasiveness of the "silent problem" even in advanced heritage speakers.

Additional trouble spots for Korean, manifested in the L2 data, included misuse of the topic marker $(\mathrm{p}<0.00001)$, unacceptable replacement of the nominative marker with the topic marker $(p<0.0001)$, and unacceptable omission of the nominative marker $(p<0.00001)$. In these conditions, L2 learners of Korean significantly diverged from the control group.

When compared with the L2 group, heritage speakers of Korean exhibited a number of advantages over L2 learners, manifested in statistically significant differences between the heritage and L2 groups on conditions that called for the nominative marker but employed the topic marker instead ( $p=0.005$ on ungrammatical misuse, $p=0.01$ on infelicitous misuse) and conditions involving unacceptable omissions of the nominative marker $(p=0.02)$. No comparable advantage was detected with unacceptable omissions of the topic marker when a between-group analysis was performed ( $p>0.5$ ). Thus, in line with the general pattern emerging in the Japanese group and with our predictions, heritage speakers of Korean were overall more accurate than L2 learners on conditions that tested the participants' knowledge of the subject marker.

Conditions involving particle omissions reveal a further asymmetry between the knowledge of the nominative marker and the topic marker in the group of Korean heritage speakers. Within-group comparisons yield a highly significant $(\mathrm{p}<0.00001)$ difference between acceptable and unacceptable omissions of the nominative case markers, suggesting that Korean heritage speakers have general knowledge of where the subject markers can and cannot be omitted. However, a non-significant difference between acceptable and unacceptable omissions of the topic markers $(\mathrm{p}=0.69)$ in the same group suggests lack of comparable knowledge for the use of null and overt topic particles. This finding is consistent with our predictions. As we discussed earlier, unacceptable omissions of the nominative case marker in its non-exhaustive reading arise from syntactic violations, whereas topic particle omissions can generally be judged as more or less acceptable relative to the larger discourse-pragmatic context of the utterance in which they occur. The topic marker has been explicitly linked to such factors as the expression of the speaker's emotions and foregrounding in discourse (Shibatani, 1990; Suzuki, 1995), factors that directly correspond to the discourse component of the grammar in (1). Heritage speakers of Korean, whose ratings on most variables approached those of the control group, appeared to have difficulties precisely with discourse-level phenomena, and not with narrow syntax.

In order to address our predictions with respect to the hierarchy of the specific functions associated with the topic and nominative case markers, we examined the ratings obtained from contexts targeting the neutral description and exhaustive listing functions of the nominative marker and the anaphoric, generic, and contrastive functions of the topic marker. Once again, we find that discourse-level phenomena appear to present more difficulty to heritage speakers than sentence-level phenomena. In Japanese as well as in Korean, heritage speakers were statistically 
more accurate on rating acceptable sentences with the descriptive $g a$ than sentences with the exhaustive listing $g a(\mathrm{p}=0.01$ in Japanese, $\mathrm{p}<0.0001$ in Korean). No statistically significant differences between the two functions of the nominative case marker were found in the L2 groups of both languages. Analysis of contexts involving omissions of the topic marker revealed further significant differences among the various functions of the topic marker, manifested in both languages only in the groups of heritage language speakers. Heritage speakers of Japanese and Korean were significantly more accurate on rating sentences involving generic topics than they were on rating sentences involving contrastive topics $(p<0.01$ for Japanese, $p<0.001$ for Korean). In heritage Korean, an additional statistical difference was found between generic and anaphoric contexts for omissions of the topic marker: Ratings of sentences involving generic topics were significantly closer to the baseline ratings than those in anaphoric contexts $(p=0.001)$. These results are suggestive of the following hierarchy, which represents the directionality of relative difficulty for the specific functions of the nominative case marker (12) and the topic marker (13):

\section{exhaustive NOM > descriptive NOM}

anaphoric TOP $>$ generic TOP; contrastive TOP $>$ generic TOP

This pattern is consistent with our predictions. The anaphoric topic marker, which refers back to previous discourse, is found to be more difficult than the topic marker that occurs in generic statements and is not linked to discourse, suggesting that heritage speakers do better with themecreation than with theme-maintenance. Generic topic is found to be less difficult for heritage speakers than contrastive topic, which marks an element that participates in a set relationship with some other element in discourse. Thus, contrastive topic exhibits a relatively greater degree of discourse dependence than generic topic. Similarly, narrow-focus ga, whose appropriate use requires keeping track of contextual information, is found to be more difficult than the sentencelevel descriptive $g a$, mediated in narrow syntax and not linked explicitly to larger discourse. This suggests, overall, that semantic and discourse computation presents more challenges than syntactic computation. In the concluding part of this article, we offer some preliminary thoughts on what contributes to the observed asymmetry and outline a direction for future investigations.

\section{Heritage Japanese and Heritage Korean: Two pathways to the heritage status}

In this section, we offer some observations that may help account for the marked contrast in the rates of accuracy exhibited by heritage speakers of Japanese and Korean, despite a comparable demographic profile of the participants in the two groups. As indicated in Table 1 above, the age and length of exposure to the heritage language are in the same range for heritage speakers in each language group. Still, our findings clearly point to differences between the two heritage languages in the degree of intergenerational language maintenance: Heritage speakers of 
Korean were more similar to native speakers in the control group and quite different from L2 learners, while heritage speakers of Japanese exhibited markedly low accuracy rates compared to baseline speakers and generally patterned with L2 learners ${ }^{4}$.

We hypothesize that this striking difference has to do with the dissimilar experiences of heritage speakers from the Japanese versus Korean communities in the U.S. The former group is predominantly composed of heritage speakers in the broad sense of the term, while the latter is comprised of heritage speakers in the narrow sense. (See Polinsky \& Kagan, (2007) for the distinction between BROAD and NARROW conceptions of heritage language.) Defined broadly, a heritage language is understood as a language of cultural significance; in Fishman's (2001) terms, this would be a language that has a particular family relevance. As such, a heritage language in a broad sense does not presuppose any linguistic knowledge by people who see it largely as a symbolic marker of cultural identity, a bridge to their cultural and ethnic roots. Despite the fact that as learners they may be more culturally motivated than an average student in a foreign language classroom, their linguistic performance at the outset may nevertheless be comparable to that of second language learners. In contrast, the narrow conception of heritage language, based on the now-classic definition of heritage speakers as bilinguals raised in homes where a non-dominant language is spoken (Valdés, 2000), is based crucially on the presence of at least some linguistic knowledge of the heritage language. Defined narrowly, a heritage language is the L1 of childhood exposure, even if the adult bilingual speaker can barely follow it. A heritage language does not necessarily include any ethnic or family relevance according to the narrow definition - a heritage speaker of Spanish raised by an Argentinian caregiver can be ethnically African American or Asian American.

The data in our study suggest that the participants in the heritage Japanese group represent a population that is more consistent with the broad definition of the heritage language, while the heritage speakers in the Korean group more closely represent its narrow conception. If this is indeed the case, then it is not surprising that participants in the heritage Japanese group did not exhibit considerable linguistic differences from L2 learners: In all likelihood, it was the cultural and symbolic link with the heritage language that motivated these people's interest in the language.

${ }^{4}$ An anonymous reviewer raised an interesting possibility that the contrast in accuracy rates between heritage Japanese and heritage Korean speakers may be due to structural differences between Japanese and Korean. In particular, the use of the topic marker in Korean is more restricted than in Japanese (as discussed in section 2). If so, the relatively more restricted distribution of TOP in Korean may play a role in facilitating the performance of Korean heritage speakers at least in some conditions. At this point, we cannot probe into this issue directly, as our stimuli were identical for Japanese and Korean, targeting only those conditions on the use of TOP and NOM that were shared by both languages. However, future studies could examine the role of cross-linguistic differences by focusing specifically on contexts where such differences exist. 
Different sociolinguistic histories of Japanese and Korean immigration to the U.S. predict different scenarios of language maintenance in the two immigrant communities. Japanese immigration to the U.S. has a long and complex history: The peak of immigration from Japan in the second half of the nineteenth century was followed by an abrupt decline in the early twentieth century, particularly after the Immigration Act of 1924, which banned Japanese immigration. Even after the Hart-Cellar Act of 1965, which abolished the quota system based on national origins, rates of Japanese immigration to the U.S. have remained relatively low. Aside from large intergenerational gaps and lack of continuity, which undoubtedly contributed to a rapid assimilation of U.S.-born children of Japanese immigrants into mainstream society, repressive language policies during and after World War II created even more unfavorable conditions for sustained language maintenance. Today, Japanese communities are generally well-integrated into mainstream American society. Based on the results of the National Heritage Language Survey (Carreira \& Kagan, 2011), Japanese heritage language learners tend to prioritize professional reasons rather than personal ones for studying their heritage language in college.

In contrast, Korean immigration to the U.S. is a relatively more recent phenomenon. Korean immigrants started arriving in large numbers after the Hart-Cellar Act of 1965, and based on the available U.S. Census data, the numbers of immigrants from Korea have continued to grow steadily in the last decades, nearly tripling between 1980 and 2007 (Table 2).

Table 2. Japanese and Korean immigration to the U.S. between 1980 and 2007. Source: American Community Survey 2007 (US Census)

\begin{tabular}{lcccc|c}
\hline $\begin{array}{l}\text { Languages } \\
\text { spoken at home }\end{array}$ & $\mathbf{1 9 8 0}$ & $\mathbf{1 9 9 0}$ & $\mathbf{2 0 0 0}$ & $\mathbf{2 0 0 7}$ & Increase (\%) \\
\hline Japanese & 336,318 & 427,657 & 477,997 & 458,717 & 36.4 \\
\hline Korean & 266,280 & 626,478 & 894,063 & $1,062,337$ & 299 \\
\hline
\end{tabular}

Existing studies indicate that first-generation immigrants, i.e., parents of heritage language speakers, tend to use predominantly Korean at home (Min 2000). Research on language maintenance in Korean communities in the U.S. suggests that communities play a large role in promoting the heritage language (Wiley, 2005; Cho, 2000). Data collected from college-aged heritage speakers of Korean as part of the National Heritage Language Survey indicate that, compared to all other heritage languages surveyed, Korean heritage language learners exhibit the highest rates of participation in a community or church school and a very high degree of involvement in community events in their heritage language (Carreira \& Kagan, 2011).

Data obtained from our sociolinguistic questionnaires, completed by all participants in our study, provide additional insights into the observed contrast in the degree of heritage language maintenance between the two language groups. Questions pertaining to the patterns of language use at home indicate a greater degree of parental involvement in the promotion of the 
heritage language, more access to schooling, and a greater desire to improve heritage language skills in the heritage Korean group than in the heritage Japanese group (Table 3).

Table 3. Results from the background questionnaire

\begin{tabular}{l|c|c}
\hline Question & Korean HS (\% YES) & Japanese HS (\% YES) \\
\hline $\begin{array}{l}\text { Did your parents encourage you to speak the HL as much as } \\
\text { possible in the house? }\end{array}$ & 56 & 44 \\
\hline Did your parents correct you when you spoke the HL? & 49 & 26 \\
\hline $\begin{array}{l}\text { Did you study the HL as a foreign language at school or } \\
\text { college? }\end{array}$ & 39 & 20 \\
\hline $\begin{array}{l}\text { Did you receive any other formal instruction in the HL (e.g., } \\
\text { Sunday school)? }\end{array}$ & 28 & 22 \\
\hline $\begin{array}{l}\text { Would you like to improve your HL skills? } \\
\text { ( } 44\end{array}$ & 37
\end{tabular}

The overall low accuracy of ratings in the heritage Japanese group compared to nearly target-like results observed in the heritage Korean group suggests that a wide variation in heritage language proficiency levels may be detected even in age-matched populations that exhibit surface similarities in language acquisition scenarios, including such pivotal factors as the age of arrival, age of switch to the dominant language, and the degree of exposure to the heritage language. Divergence in language maintenance scenarios at the community level, manifested in different rates and trajectories of intergenerational language loss for different immigrant languages in the U.S., may lead to sharp contrasts in ultimate proficiency levels exhibited by adult heritage language speakers.

\section{Conclusions}

At the outset of our investigation, we outlined a set of questions that aimed to deepen our understanding of heritage language architecture as a window into human language design. By examining linguistic phenomena mediated at different structural levels, we were able to establish that heritage speakers at varying proficiency levels, including advanced speakers, exhibit greater difficulties with semantic and discourse-pragmatic computation than with phenomena regulated entirely within narrow syntax.

What exactly contributes to this asymmetry? On the one hand, the computation of discourse-related material necessarily requires more structure-building. From this point of view, computing CP-level phenomena can be more costly than IP-level computation due to the larger size of the segment involved and a greater degree of embedding. On the other hand, the observed pattern can be attributed to the interface problem, i.e., the idea that phenomena regulated at the intersections among linguistic modules (such as syntax and semantics, syntax and pragmatics) present more challenges in language development than phenomena regulated within a single linguistic module (Sorace. 2005; Sorace \& Serratrice, 2009). Phenomena at the syntaxpragmatics interface, the so-called external interface, have been argued to pose the greatest 
challenges to language acquirers because they not only involve integrating various types of knowledge across domains, but they also require simultaneous processing of linguistic and nonlinguistic material. At this point, our findings do not provide a direct way to test these hypotheses. We leave this important question for future work.

Another significant finding of this study is quantitative evidence of differences between heritage speakers in the broad and narrow senses of the term. This distinction-between speakers who have a family connection to a language but may not have been exposed to it in a natural early setting and speakers who receive childhood exposure to the baseline language - has been proposed in preliminary literature (cf. Polinsky \& Kagan 2007), but this is the first time that it has received quantitative support from an experimental study. Our results indicate that Japanese heritage speakers fit the definition of heritage speakers in the broad sense, but they do not have any linguistic advantage when it comes to control of Japanese grammar and discourse, and they pattern with L2 speakers. Korean heritage speakers, on the other hand, are much closer to native controls and bear all the hallmarks of high proficiency heritage speakers. Quantitative support for the broad-narrow distinction is encouraging, and we hope that more studies will explore this distinction in greater detail.

\section{References}

Benmamoun, E., Montrul, S., \& Polinsky, M. (2010). Prolegomena to heritage linguistics [White paper]. University of Illinois at Urbana-Champaign and Harvard University. Retrieved from http://www.nhlrc.ucla.edu/pdf/HL-whitepaper.pdf.

Bermel, N., \& Kagan, O. (2000). The maintenance of written Russian in heritage speakers. In O. Kagan \& B. Rifkin (Eds.), The learning and teaching of Slavic languages and cultures (pp. 405-436). Bloomington, IN: Slavica.

Bowls, M. (2001). Measuring implicit and explicit knowledge. What can heritage language learners contribute? Studies in Second Language Acquisition, 33, 247-271.

Carreira, M., \& Kagan, O. (2011). The results of the National Heritage Language Survey: Implications for teaching, curriculum design, and professional development. Foreign Language Annals, 43(3), 40-64.

Chafe, W. (1973). Meaning and the structure of language. Chicago, IL: University of Chicago Press.

Cho, G. (2000). The role of heritage language in social interactions and relationships: Reflections from a language minority group. Bilingual Research Journal, 24, 333-348.

Choi, H.W. (1999). Optimizing structure in context: Scrambling and information structure. Stanford: CSLI.

Chomsky, N. (1995). The Minimalist Program. Cambridge, MA: The MIT Press.

Chomsky, N. (2000). Minimalist inquiries. In R. Martin, D. Michaels, and J. Uriagereka (Eds.), Step by step: Essays in minimalist syntax in honor of Howard Lasnik (pp. 89-155). Cambridge, MA: The MIT Press.

Chomsky, N. (2001). Derivation by phase. In M. Kenstowicz (Ed.), Ken Hale: A life in language (pp. 1-52). Cambridge, MA.: The MIT Press.

Clancy, M. (1985). The acquisition of Japanese. In D. Slobin (Ed.), The Crosslinguistic study of language acquisition. Vol. 1: The data (pp. 373-524). Hillsdale, NJ: Lawrence Erlbaum. 
Ito, T., \& Tahara, S. (1985). A psycholinguistic approach to the acquisition of multifunctionality in Japanese particles wa and ga. Descriptive and Applied Linguistics, 18, 121-131.

Fishman, J. (2001). 300-plus years of heritage language education in the United States. In J. K. Peyton, D. A. Ranard, \& S. McGinnis (Eds.), Heritage languages in America: Preserving a national resource (pp 81-89). Washington, DC \& McHenry, IL: Center for Applied Linguistics \& Delta Systems.

Frazier, L. \& Clifton, C. (1996). Construal. Cambridge, MA: The MIT Press.

Gibson, E., Piantadosi, S., \& Fedorenko, K. (2011). Using Mechanical Turk to obtain and analyze English acceptability judgments. Language and Linguistic Compass 5, 509-524.

Givón, T. (1979). On understanding grammar. New York: Academic Press.

Goto, K. (1988). Preschool children's production of the case particles ga and wo and their judgment in simple transitive sentences. MITA Working Papers in Psycholinguistics, 1, $39-49$.

Gries, S. (2009). Statistics for linguistics with R: A practical introduction. Berlin--New York: Mouton de Gruyter.

Grodzinsky, Y., \& Reinhart, T. (1993). The innateness of binding and coreference. Linguistic Inquiry, 24, 69-101.

Hirakawa, M. (2004). Acquisition of case and topic particles and development index for Japanese. In K. Otomo (Ed.), Comparative research for a developmental index for first and second language of Japanese(pp. 167-174) (Report of the Grant-in-Aid for scientific research B (1) (2001-2003) Project No. 13410034).

Inoue, K. (1983). Some discourse principles and lengthy sentences in Japanese. Papers in Linguistics, 16(1-2), 57-87.

Kim, T. (2008). Subject and object markings in conversational Korean. Ph.D. Dissertation, SUNY Buffalo.

Kim, Y. (1997). The acquisition of Korean. In D. I. Slobin (Ed.), The Crosslinguistic Study of Language Acquisition (Vol. 4, pp. 335-435). Hillsdale, NJ: Lawrence Erlbaum.

Koornneef, A. (2008). Eye-catching anaphora. Utrecht: LOT International Dissertation Series.

Kuno, S. (1972). Functional sentence perspective: A case study from Japanese and English. Linguistic Inquiry ,3, 269-320.

Kuno, S. (1973). The structure of the Japanese language. Cambridge, MA: The MIT Press.

Kuramada, C., \& Jaeger, F. (2012). Communicatively efficient language production and casemarker omission in Japanese. CogSci 12: The $34^{\text {th }}$ Annual Meeting of the Cognitive Science Society. Sapporo, August 2012.

Kuroda, S.-Y. (1965). Causative forms in Japanese. Foundations of Language, 1, 30-50.

Kuroda, S.-Y. (2005). Focusing on the matter of topic: A study of wa and ga in Japanese. Journal of East Asian Linguistics, 14, 1-58.

Laleko, O. (2010). The syntax-pragmatics interface in language loss: Covert restructuring of aspect in heritage Russian. Ph.D. Dissertation, University of Minnesota.

Laleko, O., \& Kawamura, H. (2011). Grammatical restructuring in intergenerational language shift: A case of Heritage Japanese. The 56th Annual Conference of the International Linguistics Association. Rutgers University. New Brunswick, NJ. 15-17 April.

Lambrecht, K. (1994). Information structure and sentence form: Topic, focus, and the mental representations of discourse referents. Cambridge: Cambridge University Press. 
Langacker, R. (2000). A dynamic usage-based model. In M. Barlow and S. Kemmer (Eds.), Usage-based models of language (pp. 1-64). Stanford: CSLI.

Li, C., \& Thompson, S. (1976). Subject and topic: A new typology of language. In C. N. Li (Ed.), Subject and topic(pp. 458-489). New York: Academic Press.

Maynard, S. K. (1980). Discourse functions of the Japanese theme marker 'Wa.' Ph.D. Dissertation, Northwestern University.

Min, P. G. (2000). Korean Americans' language use. In S. L. McKay \& S. C. Wong (Eds.), New immigrants in the United State,(pp. 306-332). Cambridge: Cambridge University Press.

Montrul, S. (2002). Incomplete acquisition and attrition of Spanish tense/aspect distinctions in adult bilinguals. Bilingualism: Language and Cognition, 5, 39-68.

Montrul, S. (2008). Incomplete acquisition in bilingualism: Re-examining the age factor. Amsterdam: John Benjamins.

Montrul, S., Foote, R., \& S. Perpiñán (2008). Gender agreement in adult second language learners and Spanish heritage speakers: The effects of age and context of acquisition. Language Learning: A Journal of Research in Linguistic Studies, 58, 503-553.

Montrul, S. \& S. Perpiñán (2011). Assessing differences and similarities between instructed heritage language learners and L2 learners in their knowledge of Spanish tense-aspect and mood (TAM) morphology. Heritage Language Journal, 8(1).

Morikawa, H. (1997). Acquisition of case marking and argument structure in Japanese. Tokyo: Kuroshio Shuppan.

Nakanishi, K. (2001). Prosody and information structure in Japanese: A case study of topic marker wa. In N. Akatsuka and S. Strauss (Eds.), Japanese/Korean Linguistics, (Vol. 10, pp. 434-447).

Nakamura, K. (1993). Referential structure in Japanese children's narratives: The acquisition of $w a$ and ga. In S. Choi (Ed.), Japanese/Korean Linguistics (Vol.3, pp. 84-99).

National Heritage Language Survey [data from Japanese and Korean college-level survey respondents]. Los Angeles: National Heritage Language Resource Center.

Okubo, Ai. (1967). Yoji gengo-no hattatsu. Tokyo: Tokyodo Publishers.

Polinsky, M. (1997). American Russian: Language loss meets language acquisition. In W. Browne (Ed.), Annual workshop on formal approaches to Slavic linguistics: The Cornell Meeting (pp. 370-406). Ann Arbor: Michigan Slavic Publications.

Polinsky, M. (2000). The composite linguistic profile of speakers of Russian in the US. In O. Kagan \& B. Rifkin (Eds.), The learning and teaching of Slavic languages and cultures (pp. 437-465). Bloomington, IN: Slavica.

Polinsky, M. (2006). Incomplete acquisition: American Russian. Journal of Slavic Linguistics, $14,191-262$.

Polinsky, M. (2008a). Heritage language narratives. In D. Brinton, O. Kagan, \& S. Bauckus (Eds.), Heritage language education: A new field emerging(pp. 149-164). New York: Routledge.

Polinsky, M. (2008b). Without aspect. In G. Corbett \&M. Noonan (Eds.), Case and grammatical relations (pp. 263-282). Amsterdam: John Benjamins.

Polinsky, M., \& Kagan, O. (2007). Heritage languages: In the 'wild' and in the classroom. Language and Linguistics Compass, 1(5), 368-395.

Reinhart, T. (1981). Pragmatics and linguistics:An analysis of sentence topics. Philosophica, 27, 53-94.

Reinhart, T. (1983). Anaphora and semantic interpretation. London: Croom Helm. 
Reinhart, T. (2006). Interface strategies: Optimal and costly computations. Cambridge, MA: MIT Press.

Reuland, E. (2011). Anaphora and language design. Cambridge, MA: MIT Press.

Rothman, J. (2007). Heritage speaker competence differences, language change, and input type: Inflected infinitives in Heritage Brazilian Portuguese. International Journal of Bilingualism, 11, 359-389.

Shibatani, M. (1990). The languages of Japan. Cambridge: Cambridge University Press.

Shimojo, M., \& Choi, H.W. (2000). On asymmetry in topic marking - the case of Japanese WA and Korean NUN. Proceedings of the 36th Annual Meeting of the Chicago linguistics society, 455-467.

Shimojo, M. (2006). Properties of particle 'omission' revisited. Toronto Working Papers in Linguistics, 26, 123-140.

Song, M., O'Grady W., Cho, S. \& Lee, M. (1997). The learning and teaching of Korean in community schools. In Y.-H. Kim (Ed.), Korean Language in America (Vol. 2, pp. 111-27). American Association of Teachers of Korean.

Sorace, A. (2005). Selective optionality in language development. In L. Cornips and K. Corrigan (Eds.), Syntax and variation: Reconciling the biological and the social (pp. 55-80). Amsterdam: John Benjamins.

Sorace, A., \& Serratrice, L. (2009). Internal and external interfaces in bilingual language development: Beyond structural overlap. International Journal of Bilingualism, 13, 195210.

Sprouse, J. (2011). A validation of Amazon Mechanical Turk for the collection of acceptability judgments in linguistic theory. Behavior Research Methods 43, 155-167.

Suzuki, S. (1995). The functions of topic-encoding zero-marked phrases: A study of the interaction among topic-encoding expressions in Japanese. Journal of Pragmatics, 23, 607-626.

Takahashi, T. (1975). A various phase related to the part-whole relation investigated in the Sentence. Studies in the Japanese language, 103, 1-16.

Tsutsui, M. (1984). Particle ellipses in Japanese. Ph.D. Dissertation, University of Illinois, Urbana-Champaign.

Valdés, G. (2000). Teaching heritage languages: An introduction for Slavic-language-teaching professionals. In O. Kagan \& B. Rifkin (Eds.), Learning and teaching of Slavic languages and cultures: Toward the 21st century (pp. 375-403). Bloomington, IN: Slavica.

Wiley, T. G. (2005). The reemergence of heritage and community language policy in the U.S. national spotlight. The Modern Language Journal, 89, 594-601.

Yatabe, S. (1999). Particle ellipsis and focus projection in Japanese. Language, Information, Text, 6, 79-104. 